\title{
Program semester antara: efektivitasnya terhadap penguasaan konsep mahasiswa pada mata kuliah kimia dasar
}

\author{
Evi Sapinatul Bahriah ${ }^{1 *}$, Aditya Riky Nugroho ${ }^{2}$ \\ ${ }^{1}$ Prodi Pendidikan Kimia, Fakultas Ilmu Tarbiyah dan Keguruan, Universitas Islam Negeri Syarif \\ Hidayatullah Jakarta , Jawa Barat, Indonesia \\ ${ }^{2}$ Program Studi Akuntasi, Fakultas Ekonomi, Universitas Pamulang, Banten, Indonesia \\ *Coressponding author email: evi@uinjkt.ac.id
}

\begin{tabular}{ll}
\hline Artikel info \\
\hline Received $: 5$ Juli 2019 \\
Revised $:$ 29 Oktober 2019 \\
Accepted $:$ 10 Desember 2019
\end{tabular}

Kata kunci:

Semester antara

Penguasaan konsep

Kimia dasar

\begin{abstract}
ABSTRAK
Kimia dasar merupakan salah satu mata kuliah wajib yang mengkaji konsepkonsep kimia esensial yang harus dikuasai oleh mahasiswa calon guru kimia agar menjadi guru kimia profesional dan kompeten. Rendahnya nilai mata kuliah Kimia dasar menuntut Universitas membuka progam perkuliahan semester antara. Tujuan penelitian ini yaitu untuk mengetahui bagaimana efektivitas program semester antara terhadap penguasaan konsep mahasiswa pada mata kuliah kimia dasar. Metode penelitian yang digunakan adalah deskriptif kualitatif. Subjek penelitian adalah mahasiswa program studi pendidikan kimia yang berjumlah 31 orang. Instrumen penelitian yang digunakan yaitu tes esai dan kuesioner. Data yang diperoleh dianalisis secara deskriptif. Berdasarkan hasil tes dan kuesioner menunjukkan bahwa program perkuliahan semester antara dapat meningkatkan penguasaan konsep mahasiswa pada mata kuliah kimia dasar. Hal tersebut dapat dilihat pada perolehan nilai rata-rata UTS sebesar 63.5 (kategori cukup) dan UAS sebesar 74.0 (kategori baik) dan berdasarkan hasil kuesioner menujukan bahwa mahasiswa memberikan respon positif terhadap pelaksanaan program ini.
\end{abstract}

\section{ABSTRACT}

Keywords:

Intermediate semester

Mastery concept

Basic chemistry

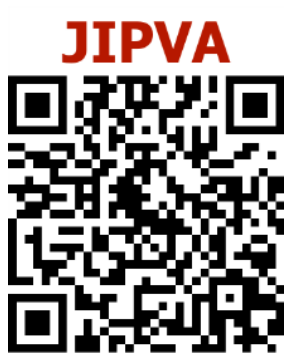

\begin{abstract}
Intermediate semester program: effectiveness on mastering student concepts in basic chemistry courses. Basic chemistry is one of the compulsory courses that study essential chemical concepts that must be mastered by prospective chemistry teacher students in order to become professional and competent chemistry teachers. Inter semester study program. The purpose of this study is to learn how to manage a semester program between fighting the mastery of student concepts in basic chemistry courses. The research method used is descriptive qualitative. The research subjects were students of chemical education study programs who studied 31 people. The research instruments used were essay tests and questionnaires. The data obtained is finished descriptively. Based on the results of tests and questionnaires show that the semester lecture program can improve students' mastery of concepts in basic chemistry courses. This can be seen in the average UTS score of 63.5 (adequate category) and UAS of 74.0 (good category) and based on the results of the questionnaire aimed at students giving a positive response to the implementation of this program.
\end{abstract}

https://doi.org/10.31331/jipva.v3i2.872

How to Cite: Bahriah, E.S \& Nugroho, A.R. (2019). Program semester antara: efektivitasnya terhadap penguasaan konsep mahasiswa pada mata kuliah kimia dasar. JIPVA (Jurnal Pendidikan IPA Veteran),3(2), 192-203. doi: https://doi.org/10.31331/jipva.v3i2.872

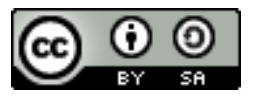

Copyright (C) 2019, Bahriah \& Nugroho 


\section{Program semester antara: efektivitasnya terhadap penguasaan konsep mahasiswa pada mata kuliah kimia dasar}

\section{PENDAHULUAN}

Standar Nasional Pendidikan Tinggi (SN-DIKTI), sebagaimana diatur dalam Permenristekdikti Nomor 44 Tahun 2015 Pasal 1, menyatakan kurikulum adalah seperangkat rencana dan pengaturan mengenai capaian pembelajaran lulusan, bahan kajian, proses, dan penilaian yang digunakan sebagai pedoman penyelenggaran program studi (Direktorat Jenderal Pembelajaran dan Kemahasiswaan, 2018). Kurikulum Pendidikan Tinggi merupakan amanah institusi yang harus senantiasa diperbaharui sesuai dengan perkembangan kebutuhan dan IPTEK yang dituangkan dalam Capaian Pembelajaran. Perguruan tinggi sebagai penghasil sumber daya manusia terdidik perlu mengukur lulusannya, apakah lulusan yang dihasilkan memiliki kemampuan sesuai dengan capaian pembelajaran yang telah dirumuskan dalam jenjang kualifikasi KKNI. Setiap perguruan tinggi wajib menyesuaikan diri dengan ketentuan tersebut (Direktorat Jenderal Pembelajaran dan Kemahasiswaan, 2018).

Kurikulum memuat standar kompetensi lulusan yang terstruktur dalam kompetensi utama, pendukung dan lainnya yang mendukung tercapainya tujuan, terlaksananya misi, dan terwujudnya visi program studi. Kurikulum juga harus dirancang berdasarkan relevansinya dengan tujuan, cakupan dan kedalaman materi, pengorganisasian yang mendorong terbentuknya hard skills dan keterampilan kepribadian dan perilaku (soft skills) yang dapat diterapkan dalam berbagai situasi dan kondisi (Kurikulum TI Unpas, 2018).

Kurikulum yang digunakan di Program Studi Pendidikan Kimia Universitas Islam Negeri Syarif Hidayatullah yaitu kurikulum berbasis KKNI (Kerangka Kualifikasi Nasional Indonesia). Prinsip dasar yang dikembangkan dalam KKNI adalah menilai unjuk kerja seseorang dalam aspek-aspek keilmuan, keahlian dan keterampilan sesuai dengan capaian pembelajaran (Learning Outcomes) yang diperoleh melalui proses pendidikan, pelatihan atau pengalaman yang telah dilampauinya, yang setara dengan deskriptor kualifikasi untuk suatu jenjang tertentu (Kemenristekdikti, 2015).

Salah satu capaian pembelajaran Program Studi Pendidikan Kimia Universitas Islam Negeri Syarif Hidayatullah yakni menerapkan konsep dasar sains dan matematika dalam penyelesaian masalah kimia. Capaian pembelajaran ini dapat tercapai dalam mata kuliah Kimia dasar, yang merupakan salah satu mata kuliah wajib yang harus diambil oleh mahasiswa Program Studi Pendidikan Kimia. Mata kuliah ini dibagi menjadi 2, yaitu Kimia dasar 1 dan Kimia dasar 2 dengan bobot SKS masing-masing adalah 3 SKS (2+1). Artinya 2 SKS tatap muka di kelas (100 menit) dan 1 SKS adalah kegiatan praktikum (150 menit).

Mata kuliah yang dikaji dalam penelitian ini yaitu Kimia dasar 1. Mata kuliah ini erat kaitannya dengan praktikum untuk memperdalam konsep, teori, maupun hukum (Zammi, Susilaningsih, \& Supardi, 2018; Sulistiana, 2018). Capaian pembelajaran mata kuliah kimia dasar yakni mahasiswa mampu memahami bahan, sifat, pengukuran, struktur atom, sistem periodik unsur, ikatan kimia, stoikiometri, sifat koligatif larutan, kesetimbangan kimia, asam basa dan konsep $\mathrm{pH}$. Berdasarkan hal tersebut, dapat diketahui bahwa kimia dasar 1 mengkaji konsep-konsep kimia esensial yang harus dikuasai mahasiswa agar menjadi calon guru kimia profesional dan kompeten, sehingga nilai kimia dasar yang diperoleh mahasiswa minimal harus B. Keberhasilan perkuliahan kimia dasar juga dapat dipengaruhi oleh faktor dari dalam 
diri mahasiswa (Syofyan, 2018). Oleh karena itu, mahasiswa harus mampu menumbuhkan motivasi berprestasi dalam perkuliahan kimia dasar (Eliyarti \& Rahayu, 2019)

Akan tetapi berdasarkan observasi dan wawancara dengan mahasiswa angkatan 2017, hampir 50\% yang mendapatkan nilai kimia dasr 1 di bawah B. Rendahnya nilai mata kuliah ini disebabkan mahasiswa belum terbiasa dengan pola pembelajaran di universitas, metode pembelajaran yang digunakan dosen kurang menarik, sarana prasarana perkuliahan maupun laboratorium yang terbatas. Sari \& Wulanda (2019) menyatakan bahwa konsep materi yang abstrak dan pembelajaran yang teacher-centered serta rendahnya kemampuan mahasiswa dalam mewujudkan gagasan baik saat pembelajaran maupun pada diskusi kelompok juga merupakan penyebab rendahnya hasil belajar kimia (Atika \& Kamaruzzaman, 2014). Mahasiswa seharusnya menguasai konsep materi perkuliahan dengan baik (Permana, Hindun, Rofiah, \& Azizah, 2019). Namun pada pembelajaran, mahasiswa cenderung menghafal rumus yang diberikan sehingga saat diminta untuk menggunakan rumus tersebut dalam konteks yang berbeda atau diubah mahasiswa merasa kesulitan (Widiyawati, Nurwahidah, \& Sari, 2019). Kesulitan dalam pelaksanaan praktikum juga menjadi penyebab konsep kimia susah dipahami oleh mahasiswa dengan baik. Pada kegiatan praktikum, hanya sedikit mahasiswa yang terlibat langsung dalam melakukan eksperimen, sebagian besar di antaranya hanya memposisikan diri sebagai observer dan pencatat data (Susbiyanto \& Wilujeng, 2013).

Oleh karena itu, dalam rangka memberikan kesempatan kepada mahasiswa untuk dapat memperbaiki nilai mata kuliah yang pernah ditempuh dan agar dapat meningkatkan indeks prestasi kumulatif (IPK) serta mempercepat kelulusan dengan kualitas yang baik maka Program studi pendidikan kimia membuka program semester antara.

Semester antara atau yang dulu dikenal dengan istilah semester pendek adalah proses penyelenggaraan pendidikan yang sesuai dengan sistem kredit. Semester antara merupakan proses perkuliahan yang dilaksanakan dalam waktu/jadwal yang singkat/dipadatkan di luar jadwal regular. Program ini diperuntukkan bagi mahasiswa yang ingin melengkapi sks akademik atau memperbaiki nilai yang sudah diperoleh pada semester sebelumnya (Himmi, 2017).

Beban studi mahasiswa, beban kerja tentang pengajar dan beban lembaga penyelenggara program dinyatakan dalam suatu kredit baik itu untuk kelas remedial maupun kelas akselerasi. Kelas remedial adalah kelas semester antara yang pesertanya adalah mahasiswa yang pernah mengambil mata kuliah dan bermaksud untuk memperbaiki nilai karena nilai sebelumnya adalah C, D, E. Sedangkan kelas akselerasi adalah kelas semester antara yang pesertanya adalah mahasiswa yang belum pernah mengambil mata kuliah dengan ketentuan indeks prestasi kumulatif (IPK) nya minimal 3,00 (Universitas Sultan Ageng Tirtayasa, 2018).

Penelitian terdahulu telah mengkaji pembelajaran mata kuliah kimia dasar dan efektivitas program semester antara. Aktivitas dan hasil belajar kimia dasar mahasiswa meningkat melalui pembelajaran kooperatif (Sudiana, 2012). Motivasi yang tinggi dibutuhkan pada diri mahasiswa agar dapat mengikuti perkuliahan kimia dasar dengan maksimal (Eliyarti \& Rahayu, 2019). 


\section{Program semester antara: efektivitasnya terhadap penguasaan konsep mahasiswa pada mata kuliah kimia dasar}

Mahasiswa dengan gaya belajar kinestetik mampu menguasai mata kuliah kimia dasar dengan baik (Sulistiana, 2018). Proses perkuliahan kimia dasar harus dapat mengakomodasi kegiatan mahasiswa dalam mengkonstruk pengetahuannya (Seery, 2015). Sementara itu, hasil temuan dari penelitian Atika \& Kamaruzzaman (2014) menunjukkan adanya hubungan positif antara keterampilan kognitif dengan kemampuan mewujudkan gagasan pada mahasiswa semester pendek. Pemahaman konsep mahasiswa meningkat melalui pembelajaran inqury terbimbing media animasi pada semester pendek (Pathoni, 2015). Namun, belum ada kajian mengenai efektivitas program semester antara terhadap penguasaan konsep mata kuliah kimia dasar. Oleh karena itu, peneliti tertarik untuk mengkaji bagaimana efektivitas program perkuliahan semester antara terhadap peningkatan penguasaan konsep mahasiswa pada mata kuliah kimia dasar 1.

\section{METODE}

\section{Metode Penelitian}

Metode penelitian yang digunakan adalah metode deskriptif kualitatif, karena bertujuan untuk menggambarkan secara sistematis fakta dan karakteristik objek atau subjek yang diteliti secara tepat (Sukardi, 2013). Penelitian deskriptif juga tidak bermaksud menguji suatu hipotesis, namun hanya menggambarkan apa adanya kejadian, variabel, atau keadaan (Arikunto, 2014).

\section{Waktu dan Tempat Penelitian}

Penelitian ini dilakukan pada tanggal 17 Juli-16 Agustus 2018 di Jurusan Pendidikan Kimia Semester Antara Ganjil tahun akademik 2017/2018 Fakultas Ilmu Tarbiyah dan Keguruan UIN Syarif Hidayatullah Jakarta.

\section{Populasi dan Sampel}

Populasi pada penelitian ini yaitu seluruh mahasiswa jurusan pendidikan IPA Fakultas Ilmu Tarbiyah dan Keguruan UIN Syarif Hidayatullah Jakarta. Sedangkan sampel penelitian ini adalah 31 mahasiswa Jurusan Pendidikan Kimia Fakultas Ilmu Tarbiyah dan Keguruan UIN Syarif Hidayatullah Jakarta yang diambil dengan teknik purposive sampling.

\section{Prosedur Penelitian}

Terdapat tiga tahap dalam penelitian ini, yaitu persiapan, pelaksanaan, dan penyelesaian. Pada tahap persiapan dilakukan: analisis capaian pembelajaran program studi

(Program Learning Outcome, PLO), analisis capaian pembelajaran mata kuliah (Course Learning Outcome, CLO), analisis metode dan strategi yang digunakan dalam pembelajaran, membuat instrumen berupa lembar soal esai dan kuesioner, pembuatan rencana perkuliahan semester (RPS), dan validasi instrumen.

Pada tahap pelaksanaan dilakukan perkuliahan semester pendek sebanyak 16 kali pertemuan termasuk Ujian Tengah Semester (UTS) dan Ujian Akhir Semester (UAS) serta pengisian lembar kuesioner di akhir perkuliahan. Sedangkan pada tahap penyelesaian dilakukan: pengolahan data, analisis data, dan menyimpulkan hasil penelitian. Secara garis besar prosedur penelitian yang dilakukan disajikan pada gambar 1 . 


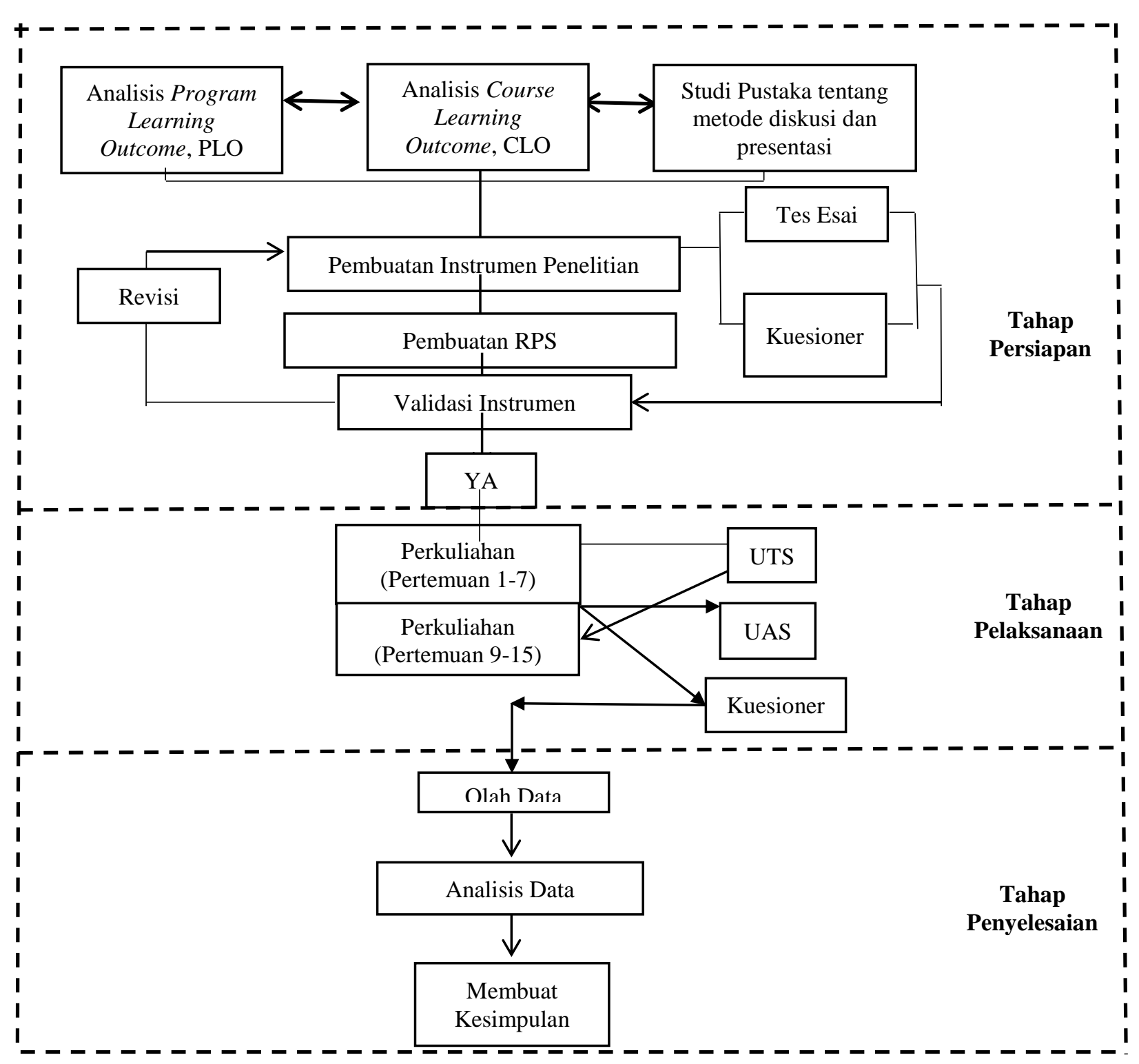

Gambar 1. Bagan Prosedur Penelitian

\section{Data, Instrumen dan Teknik Pengumpulan Data}

Instrumen yang digunakan adalah soal esai dan kuesioner. Soal esai digunakan untuk melihat bagaimana penguasaan konsep kimia dasar mahasiswa dan diberikan pada saat ujian tengah semester (UTS) serta ujian akhir semester (UAS). Kisi-kisi soal esai yang digunakan pada saat UTS dan UAS disajikan pada tabel 1. 
Tabel 1. Kisi-kisi Soal Esai UTS dan UAS

\begin{tabular}{|c|c|c|c|c|}
\hline No & Capaian Pembelajaran & No Soal & $\sum$ Soal & $\begin{array}{l}\text { Jenis } \\
\text { Uiian }\end{array}$ \\
\hline 1 & $\begin{array}{l}\text { Mengklasifikasi materi berdasarkan sifat fisik dan kimia serta } \\
\text { perubahannya }\end{array}$ & 1 & 1 & \multirow{4}{*}{ UTS } \\
\hline 2 & Menentukan tata nama senyawa berdasarkan aturan IUPAC & 2 & 1 & \\
\hline 3 & Menjelaskan sistem periodik unsur dan sifat-sifatnya & 3,4 & 2 & \\
\hline 4 & $\begin{array}{l}\text { Menentukan jenis ikatan kimia berdasarkan unsur penyusun serta } \\
\text { menghubungkan dengan sifat kimia dan fisika molekul }\end{array}$ & 5 & 1 & \\
\hline 5 & $\begin{array}{l}\text { Menjelaskan hukum dasar dan konsep mol dalam perhitungan } \\
\text { kimia (Stoikiometri) }\end{array}$ & 6,7 & 2 & \\
\hline 6 & $\begin{array}{l}\text { Mampu menganalisis sifat larutan berdasarkan jumlah zat terlarut } \\
\text { (Sifat koligatif larutan) }\end{array}$ & 1,2 & 2 & \multirow{3}{*}{ UAS } \\
\hline 7 & $\begin{array}{l}\text { Mampu meramalkan pergeseran kesetimbangan berdasarkan azas } \\
\text { Le Chatelier }\end{array}$ & 3,4 & 2 & \\
\hline 8 & $\begin{array}{l}\text { Mampu menerapkan konsep asam basa dalam reaksi dan } \\
\text { perhitungan kimia }\end{array}$ & $5,6,7$ & 3 & \\
\hline
\end{tabular}

Sedangkan kuesioner digunakan untuk melihat bagaimana pendapat mahasiswa terhadap efektivitas program perkuliahan semester antara. Kuesioner terdiri dari 40 butir pernyataan yang disusun dengan menggunakan skala Guttman ( $\mathrm{Ya}=1$, Tidak=0). Instrumen soal esai dan kuesioner sebelum digunakan divalidasi terlebih dahulu oleh dua orang ahli. Kisi-kisi kuesioner yang digunakan dapat dilihat pada tabel 2 .

Tabel 2. Kisi-kisi Kuesioner

\begin{tabular}{lc}
\multicolumn{1}{c}{ Aspek } & No Pernyataan \\
$\begin{array}{l}\text { Latar belakang mengikuti program perkuliahan semester } \\
\text { antara }\end{array}$ & $1,2,3,4$ \\
Latar belakang rendahnya nilai mata kuliah kimia dasar & $5,6,7,8,9,10,11,12,13,14,15$, \\
& $16,17,18$ \\
Program perkuliahan semester antara yang pernah diikuti & $19,20,21$ \\
$\begin{array}{l}\text { Metode dan strategi program perkuliahan semester antara } \\
\text { Harapan dalam mengikuti program perkuliahan semester } \\
\text { antara }\end{array}$ & $22,23,24,25,26,27,28,29,30$ \\
Efektivitas program perkuliahan semester antara & $31,32,33,34$ \\
\hline & Jumlah Pernyataan \\
\hline
\end{tabular}

\section{Teknik Analisis Data}

Data hasil tes esai dan kuesioner kemudian dihitung persentasenya dan dianalisis dengan menggunakan teknik analisis deskriptif. Persentase yang diperoleh kemudian ditafsirkan kedalam lima kategori, yaitu: baik sekali (80-100), baik (66-79), cukup (56-65), kurang (4055), dan kurang sekali (0-39) (Arikunto, 2018).

\section{HASIL DAN PEMBAHASAN}

Program perkuliahan semester antara diadakan dalam rangka memberikan kesempatan kepada mahasiswa untuk dapat memperbaiki nilai mata kuliah kimia dasar yang pernah ditempuh. Perkuliahan dilakukan sebanyak 16 kali pertemuan, termasuk Ujian Tengah 
Semester (UTS) dan Ujian Akhir Semester (UAS). UTS dilakukan pada pertemuan 8, UAS dan kuesioner dilakukan pada pertemuan 16.

Efektivitas program perkuliahan semester antara dapat dilihat dari tiga indikator, yaitu nilai formatif, nilai UTS dan nilai UAS. UTS dan UAS diberikan untuk mengetahui tingkat penguasaan konsep mahasiswa sebagai salah satu tolak ukur capaian pembelajaran (Prasetyono, 2017). Sedangkan untuk penilaian formatif diperoleh dari jumlah kehadiran mahasiswa, tugas individu, dan presentasi. Rata-rata persentase nilai formatif, UTS dan UAS dapat dilihat pada gambar 2.

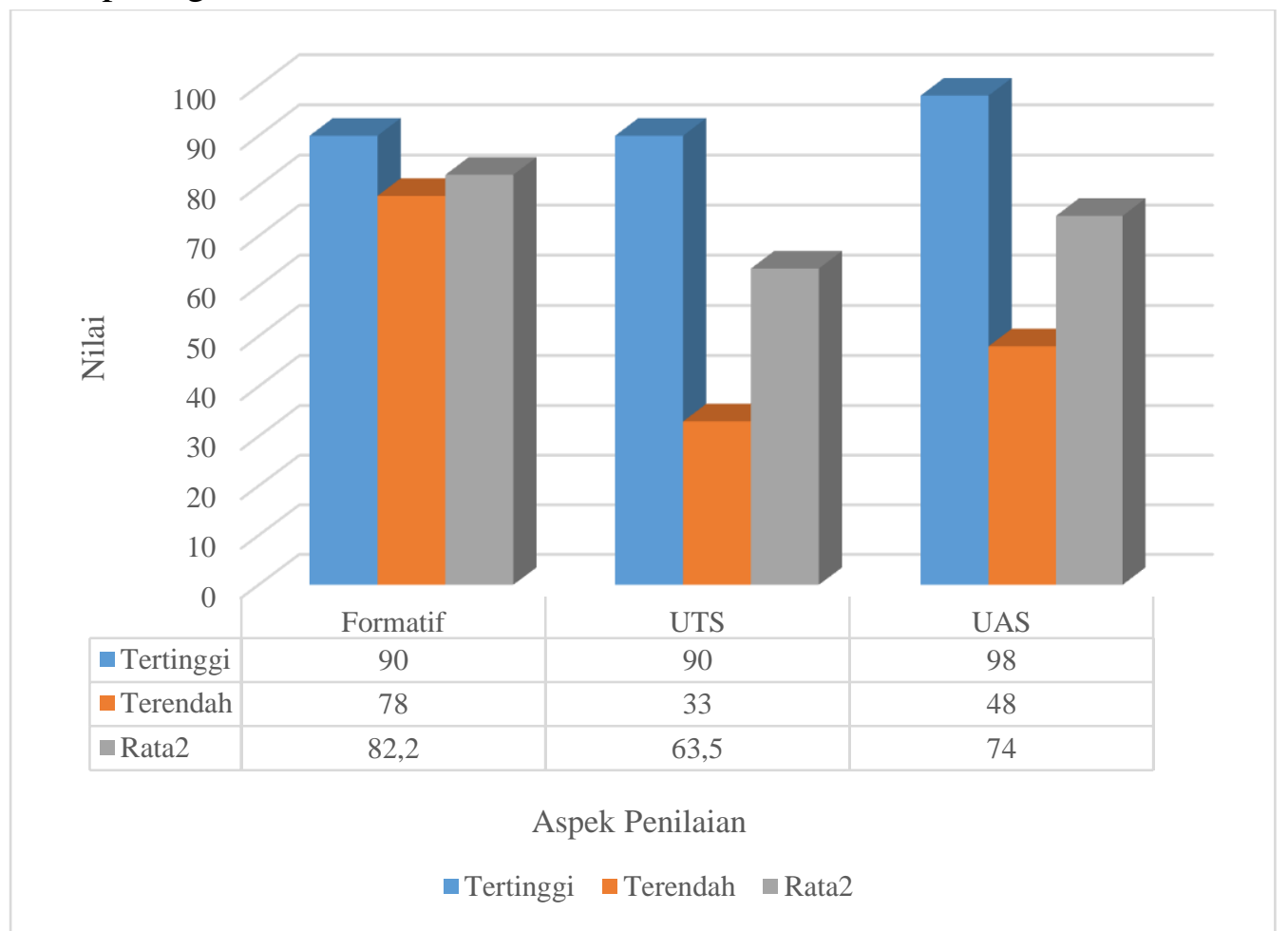

Gambar 2. Data Nilai Formatif, UTS, dan UAS

Berdasarkan nilai formatif, UTS, dan UAS dapat diketahui bahwa nilai persentase ratarata secara berurutan adalah 82,$2 ; 63,5$; dan 74 . Tiga komponen nilai ini dihitung nilai akhirnya, dengan menggunakan pembobotan nilai 40:30:30 maka dari 31 orang mahasiswa masih ada yang mendapatkan nilai $\mathrm{C}$ sebanyak 3 orang dan nilai D sebanyak 1 orang. Hal ini dikarenakan tidak semua mahasiswa mampu menguasai materi dalam waktu yang padat dan singkat. Mahasiswa dengan kategori slow learner akan memperoleh nilai yang rendah dan sebaliknya (Hasyim, Mulya, \& Wahyono, 2015). Hal ini senada dengan temuan Atika \& Kamaruzzaman (2014) yang menunjukkan adanya hubungan positif antara keterampilan kognitif dengan kemampuan merealisasikan gagasan pada mahasiswa. Ini berarti semakin tinggi keterampilan kognitif yang dimiliki mahasiswa, semakin baik pula kemampuan mahasiswa dalam mewujudkan gagasan yang dimiliki. Sebaliknya, semakin rendah keterampilan kognitif yang dimiliki mahasiswa maka semakin kurang pula kemampuannya dalam mewujudkan gagasan yang dimilikinya.

Adapun informasi efektif atau tidaknya program semester antara yang dilaksanakan dapat diperoleh dari data hasil kuesioner. Kuesioner ini diisi oleh mahasiswa di akhir pelaksanaan 


\section{Program semester antara: efektivitasnya terhadap penguasaan konsep mahasiswa pada mata kuliah kimia dasar}

semester pendek. Kuesioner ini terdiri dari 6 aspek. Data hasil kuesioner mahasiswa disajikan pada tabel 3.

Tabel 3. Data Perolehan Kuesioner Mahasiswa pada Tiap Aspek

\begin{tabular}{clc}
\hline No & \multicolumn{1}{c}{ Aspek } & \% Rata-rata \\
1 & Latar belakang mengikuti Program Perkuliahan Semester Antara & 70.16 \\
2 & Latar belakang rendahnya nilai mata kuliah Kimia dasar & 49.31 \\
3 & Program Perkuliahan Semester Antara yang pernah diikuti & 38.71 \\
4 & Metode dan Strategi Program Perkuliahan Semester Antara & 74.19 \\
5 & Harapan dalam Mengikuti Program Perkuliahan Semester Antara & 100 \\
6 & Efektivitas Program Perkuliahan Semester Antara & 83.87 \\
\hline & Rata-rata & $\mathbf{6 6 . 4 5}$ \\
\hline
\end{tabular}

Berdasarkan data hasil kuesioner diperoleh rata-rata sebesar 66.45 dengan kategori baik. Artinya hampir semua mahasiswa yang mengikuti program semester pendek ini memberikan respon yang positif. Kuesioner ini memuat 6 aspek, dimana pada aspek pertama (Latar belakang) diperoleh rata-rata sebesar 70.16. Hal ini ditunjukan bahwa dari 31 orang mahasiswa menyatakan bahwa latar belakang mengikuti program semester pendek ini adalah untuk selain memperbaiki nilai mata kuliah yang kurang, nilai mata kuliah Kimia dasar yang diperoleh di bawah $70(\mathrm{C})$, juga untuk meningkatkan pemahaman konsep.

Aspek kedua, yaitu latar belakang rendahnya nilai mata kuliah Kimia dasar diperoleh ratarata sebesar 49.31. Hal ini disebabkan oleh banyak faktor, diantaranya: (1) Program studi Pendidikan Kimia bukan pilihan pertama dalam seleksi masuk perguruan tinggi sehingga mahasiswa kurang termotivasi dalam belajar. Padahal untuk memperoleh nilai IPK tinggi, di antaranya mahasiswa harus belajar secara maksimal sesuai dengan program studi yang dipilih. Oleh karena itu, jurusan/program studi yang dipilih harus diminati dan sesuai dengan bidang keahlian serta memiliki korelasi dengan latar belakang pendidikan mahasiswa (Buaton, Sihombing, Aritonang, \& Wijaya, 2018). (3) Sebagian besar materi perkuliahan kimia dasar bersifat abstrak, memuat simbol dan rumus kimia sehingga mahasiswa sulit menerapkan teori maupun rumus kedalam soal (Sari \& Sugiyarto, 2015). Selain itu, mahasiswa kesulitan memahami konsep-konsep kimia karena ketidakmampuan menghubungkan dunia makroskopis dan mikroskopis (Prasetya, Subandi, \& Munzil, 2017). (4) Metode pembelajaran yang dilakukan dosen selama perkuliahan kimia dasar monoton dan kurang menarik serta sulit untuk memahami penjelasan dosen (Yulina, Permanasari, Hernani, \& Setiawan, 2019). Metode pembelajaran yang dilakukan dosen selama perkuliahan adalah ceramah. Metode ceramah memiliki kelemahan, diantaranya bersifat teacher center sehingga hanya terjadi komunikasi satu arah yang menyebabkan mahasiswa menjadi kurang aktif dan monoton (Devi, 2010). (5) Belum terbiasa mempelajari satu konsep kimia dalam satu kali tatap muka. (6) Kesulitan dalam mengikuti kegiatan praktikum kimia dasar. (7) Sarana dan prasarana yang ada dalam program studi pendidikan kimia kurang lengkap dan kurang menunjang perkuliahan Kimia dasar. Hal ini senada dengan hasil penelitian yang dilakukan oleh Anggraeni (2016) yang menyatakan bahwa hambatan yang menyebabkan kesulitan belajar kimia dasar adalah penguasaan materi. Persentase kesulitan diperoleh dari (1) proses pelaksanaan praktikum 53,29\%, (2) proses pembelajaran 8,69\%, dan (3) pelaksanaan praktikum sebesar $66,26 \%$. (8) Media yang digunakan dalam perkuliahan kimia dasar sebatas 
PPT. Padahal penggunaan media yang relevan akan menjadikan proses belajar mengajar yang efektif (mencapai tujuan) (Widiyawati \& Nurwahidah, 2018) dan efesien (mudah dan cepat) (Wulandari, Widiyawati, \& Sari, 2019).

Hal ini sesuai dengan hasil penelitian yang dilakukan oleh Ristiyani \& Bahriah (2016) yang menyatakan rata-rata untuk tiap indikator yang teridentifikasi menyebabkan kesulitan belajar siswa pada mata pelajaran kimia diantaranya faktor fisiologis (jasmani/panca indera) sebesar 74,5\% (Kategori tinggi), psikologi 69,78\% (Kategori sedang), aspek sosial 68\% (Kategori sedang), sarana dan prasarana 58,75\% (Kategori sedang), metode belajar $77 \%$ (Kategori tinggi), dan guru sebesar 77,17\% (Kategori tinggi).

Aspek ketiga, yaitu Program Perkuliahan Semester Antara yang pernah diikuti diperoleh rata-rata sebesar 38.71. Hal ini dapat diketahui bahwa hampir semua mahasiswa baru pertama kali mengikuti program semester pendek Kimia dasar.

Aspek keempat, yaitu Metode dan Strategi Program Perkuliahan Semester Antara diperoleh rata-rata sebesar 74.19. Hal ini dapat diketahui bahwa metode diskusi dan presentasi yang digunakan selama perkuliahan sangat menarik dan tidak monoton. Hal ini dikarenakan metode diskusi dan presentasi dapat mendorong mahasiswa dalam mengekspresikan pendapatnya secara bebas, mendorong mahasiswa menyumbangkan buah pikirannya untuk memecahkan masalah bersama, membantu dalam memahami konsep Kimia dasar, dan melatih untuk berani mengemukakan pendapat dimuka umum. Hal ini sesuai dengan hasil penelitian (Berlianti, 2016) yang menyimpulkan bahwa penerapan metode presentasi dan diskusi kelas dapat memperbaiki kualitas pembelajaran dengan meningkatnya keaktifan dan hasil belajar kognitif mahasiswa. (Mitasari \& Prasetiyo, 2016) menyimpulkan bahwa penerapan metode diskusi-presentasi dipadu dengan analisis kritis artikel dapat meningkatkan pemahaman konsep, kemampuan berpikir kritis, dan komunikasi mahasiswa.

Aspek kelima, yaitu Harapan dalam Mengikuti Program Perkuliahan Semester Antara diperoleh rata-rata sebesar $100 \%$. Hal ini ditunjukan bahwa seluruh mahasiswa sangat berharap jika mengikuti program perkuliahan semester pendek dapat mempercepat kelulusan, memperbaiki nilai mata kuliah Kimia dasar yang kurang, dan meningkatkan pemahaman konsep Kimia dasar.

Adapun pada aspek yang keenam diperoleh rata-rata sebesar 83,87. Hal ini dapat diketahui bahwa Program Perkuliahan Semester Antara efektif mendongkrak nilai mata kuliah Kimia dasar, meningkatkan pemahaman materi dalam mata kuliah Kimia dasar walaupun dilakukan pemadatan jumlah tatap muka (3x/pekan), dan biaya semester antara yang dibebankan kepada mahasiswa yaitu 35.000/SKS tidak membebani mahasiswa. Oleh karena itu program semester antara ini efektif untuk meningkatkan penguasaan konsep pada mata kuliah Kimia dasar. Hal ini sesuai dengan penelitian yang dilakukan oleh (Firmansyah, 2014) yang menunjukkan bahwa $74 \%$ mahasiswa yang melaksanakan semester pendek nilainya meningkat, peningkatan mencapai 6 tingkat, sehingga bisa dikatakan semester pendek efektif untuk memperbaiki nilai.

Adapun faktor-faktor yang mempengaruhi semester antara terdiri dari faktor internal dan external. Faktor iternal terdiri dari faktor fisiologis (fisik) dan psikologis yang terdiri dari motivasi, minat (Nugraheni \& Winarni, 2018) dan sikap mahasiswa dalam melaksanakan semester pendek. Sedangkan faktor eksternal meliputi faktor sosial (lingkungan sosial 


\section{Program semester antara: efektivitasnya terhadap penguasaan konsep mahasiswa pada mata kuliah kimia dasar}

kampus, lingkungan sosial masyarakat dan lingkungan sosial keluarga), dan faktor non-sosial (lingkungan alamiah, faktor instrumental dan faktor materi pelajaran) (Firmansyah, 2014).

\section{SIMPULAN DAN SARAN}

\section{Simpulan}

Berdasarkan hasil tes dan kuesioner menunjukkan bahwa program perkuliahan semester antara dapat meningkatkan penguasaan konsep mahasiswa pada mata kuliah kimia dasar. Hal tersebut dapat dilihat pada perolehan nilai rata-rata UTS sebesar 63.5 (Kategori cukup) dan UAS sebesar 74.0 (Kategori baik) dan berdasarkan hasil kuesioner menujukan bahwa mahasiswa memberikan respon positif terhadap pelaksanaan program ini.

\section{Saran}

Untuk mengetahui seberapa efektif program perkuliahan semester antara maka perlu dilakukan uji statistik pada nilai hasil belajar sebelum dan setelah perkuliahan dilakukan.

\section{DAFTAR PUSTAKA}

Arikunto, S. (2014). Prosedur penelitian Suatu Pendekatan Praktik. Jakarta: Rineka Cipta.

Arikunto, S. (2018). Dasar-Dasar Evaluasi Pendidikan (Edisi 3). Jakarta: Bumi Aksara.

Atika, A., \& Kamaruzzaman, K. (2014). Hubungan keterampilan kognitif dengan kemampuan mewujudkan gagasan pada mahasiswa semester pendek program studi BK STKIP-PGRI Pontianak tahun 2011/2012. Sosial Horizon: Jurnal Pendidikan Sosial, 1(1), 13-22.

Berlianti, N. A. (2016). Perbaikan kualitas pembelajaran ilmu pengetahuan lingkungan melalui metode presentasi dan diskusi kelas. Ed-Humanistics: Jurnal Ilmu Pendidikan, $1(2)$.

Buaton, R., Sihombing, A., Aritonang, F. D., \& Wijaya, C. R. (2018). Data mining untuk menentukan korelasi (confidence dan support) jurusan siswa pada tingkat sekolah menengah terhadap indeks prestasi kumulatif (IPK) di perguruan tinggi sebagai solusi tepat pemilihan program studi di perguruan tinggi. JSIK (Jurnal Sistem Informasi Kaputama), 1(2), 1-13.

Devi, P. K. (2010). Metode-metode dalam Pembelajaran IPA untuk Guru SD. Jakarta: Pusat Pengembangan dan Pemberdayaan Pendidik dan Tenaga Kependidikan Ilmu Pengetahuan Alam (PPPPTK IPA).

Direktorat Jenderal Pembelajaran dan Kemahasiswaan. (2018). Buku panduan penyusunan kurikulum pendidikan tinggi. Jakarta: Direktorat Jenderal Pembelajaran dan Kemahasiswaan Kementerian Riset Teknologi dan Pendidikan Tinggi.

Eliyarti, E., \& Rahayu, C. (2019). Tinjauan motivasi berprestasi mahasiswa teknik dalam perkuliahan kimia dasar. Jurnal Pendidikan Glasser, 3(2), 196-204. https://doi.org/10.32529/glasser.v\%vi\%i.342

Firmansyah, R. (2014). Efektivitas semester pendek terhadap perbaikan nilai matakuliah pada mahasiswa program studi S1 pendidikan teknik bangunan. Fakultas Teknik UM.

Hasyim, N., Mulya, A. S., \& Wahyono, S. (2015). Penerapan model pendidikan inklusi berbasis potensi peserta didik bagi mahasiswa lamban belajar Politeknik Negeri Jakarta. Epigram, 12(1), 21-26.

Himmi, N. (2017). Korelasi self efficacy terhadap kemampuan penalaran matematis mahasiswa semester pendek mata kuliah trigonometri UNRIKA. PYTHAGORAS, 6(20), 
$143-150$.

Kemenristekdikti. (2015). Peraturan menteri riset teknologi pendidikan tinggi nomor 44 tahun 2015 tentang KKNI.

Kurikulum TI Unpas. (2018). Retrieved from https://ti.unpas.ac.id/kurikulum/

Mitasari, Z., \& Prasetiyo, N. A. (2016). Penerapan metode diskusi-presentasi dipadu analisis kritis artikel melalui lesson study untuk meningkatkan pemahaman konsep, kemampuan berpikir kritis, dan komunikasi. Jurnal Bioedukatika, 4(1), 11-14.

Nugraheni, D., \& Winarni, D. S. (2018). Pengembangan bahan ajar science teacherpreneurship berbasis karakter bagi mahasiswa pendidikan IPA. Prosiding Seminar Nasional Dan Entrepreneurship VI Tahun 2019, 1-5.

Pathoni, H. (2015). Peningkatan pemahaman konsep fisika dan aktifitas mahasiswa dengan model pembelajaran inquiry terbimbing media animasi. Jurnal Inovasi Dan Pembelajaran Fisika, 2(2), 119-122.

Permana, T. I., Hindun, I., Rofiah, N. L., \& Azizah, A. S. N. (2019). Critical thinking skills : The academic ability, mastering concepts, and analytical skill of undergraduate students. JPBI (Jurnal Pendidikan Biologi Indonesia), 5(1), 1-8. https://doi.org/10.22219/jpbi.v5i1.7626

Prasetya, F. B., Subandi, S., \& Munzil, M. (2017). Pengaruh representasi mikroskopik dinamik dan statik melalui strategi react terhadap hasil belajar dan motivasi belajar mahasiswa pada materi elektrokimia. Jurnal Pembelajaran Sains, 1(2), 26-33. https://doi.org/10.17977/um033v1i2p26-33

Prasetyono, R. N. (2017). Miskonsepsi mahasiswa teknik informatika pada materi kelistrikan. JIPVA (Jurnal Pendidikan IPA Veteran), 1(35), 1-8. https://doi.org/10.31331/jipva.v1i1.516

Ristiyani, E., \& Bahriah, E. S. (2016). Analisis kesulitan belajar kimia siswa di SMAN X Kota Tangerang Selatan. Jurnal Penelitian Dan Pembelajaran IPA, 2(1), 18-29.

Sari, D. S., \& Sugiyarto, K. H. (2015). Pengembangan multimedia berbasis masalah untuk meningkatkan motivasi belajar dan kemampuan berpikir kritis siswa. Jurnal Inovasi Pendidikan IPA, 1(2), 153. https://doi.org/10.21831/jipi.v1i2.7501

Sari, D. S., \& Wulanda, M. N. (2019). Pengembangan lembar kerja mahasiswa berbasis proyek dalam meningkatkan kemampuan berfikir kreatif mahasiswa. Natural: Jurnal Ilmiah Pendidikan IPA, 6(1), 20-33. https://doi.org/10.30738/natural.v6i1.4073

Seery, M. K. (2015). Research and Practice Flipped learning in higher education chemistry: emerging trends and potential directions. Chemistry Education Research and Practice, 16, 758-768. https://doi.org/10.1039/c5rp00136f

Sudiana, I. K. (2012). Upaya pengembangan soft skills melalui implementasi model pembelajaran kooperatif untuk peningkatan aktivitas dan hasil belajar mahasiswa pada pembelajaran kimia dasar. Jurnal Pendidikan Indonesia, 1(2), 91-101.

Sukardi, S. (2013). Metode Penelitian Pendidikan. Jakarta: Bumi Aksara.

Sulistiana, D. (2018). Analisis gaya belajar mahasiswa dan hubungannya dengan hasil belajar kimia dasar mahasiswa program studi ilmu ternak fakultas peternakan Universitas Islam Balitar semester ganjil tahun akademik 2016-2017. KONSTRUKTIVISME, 10(1), 84-97.

Susbiyanto, S., \& Wilujeng, I. (2013). Pengembangan perangkat IPA berbasis kurikulum 


\section{Program semester antara: efektivitasnya terhadap penguasaan konsep mahasiswa pada mata kuliah kimia dasar}

2013 untuk meningkatkan keterampilan proses, kejujuran, dan tanggung jawab. Jurnal Pendidikan Karakter, VI(1), 86-103. https://doi.org/10.21831/jpk.v0i1.10735

Syofyan, H. (2018). Analisis gaya belajar dan motivasi berprestasi terhadap hasil belajar IPA. Jurnal Eduscience, 3(2), 76-85.

Universitas Sultan Ageng Tirtayasa. (2018). Prosedur Proses Perkuliahan (PPK) Semester Pendek Peraturan Rektor UNTIRTA no. 04 tahun 2018 Tentang penyeenggaraan Semester Antara Tahun 2018.

Widiyawati, Y., \& Nurwahidah, I. (2018). Elclivs berbasis inquiry untuk meningkatkan penguasaan konsep siswa tuna netra pada materi rangkaian listrik. Jurnal Inovasi Pendidikan IPA, 4(2), 212-223.

Widiyawati, Y., Nurwahidah, I., \& Sari, D. S. (2019). Pengembangan instrumen integrated science test tipe pilihan ganda beralasan untuk mengukur HOTS peserta didik. Saintifika, 21(2), 1-14. Retrieved from https://jurnal.unej.ac.id/index.php/STF/article/view/13394

Wulandari, P., Widiyawati, Y., \& Sari, D. S. (2019). Pengembangan LKPD berbasis nature of science untuk meningkatkan keterampilan proses sains. Saintifika, 21(2), 23-34. https://doi.org/10.19184/saintifika.v21i2.13562.

Yulina, I. K., Permanasari, A., Hernani, H., \& Setiawan, W. (2019). Analytical thinking skill profile and perception of pre service chemistry teachers in analytical chemistry learning. IOP Conf. Series: Journal of Physics: Conf. Series, 1-7. https://doi.org/10.1088/1742$6596 / 11574 / 042046$

Zammi, M., Susilaningsih, E., \& Supardi, K. I. (2018). Jurnal Profesi Keguruan. Jurnal Profesi Keguruan, 4(1), 37-41.

\section{PROFIL SINGKAT}

Evi Sapinatul Bahriah, lahir di Serang, 7 Juli 1985, meraih gelar Sarjana Pendidikan (S.Pd) jurusan Pendidikan Kimia pada tahun 2009 di UIN Syarif Hidayatullah Jakarta dan Magister Pendidikan (M.Pd) jurusan Pendidikan IPA Konsentrasi Pendidikan Kimia SL di Universitas Pendidikan Indonesia pada tahun 2012. Saat ini bekerja sebagai dosen di jurusan Pendidikan Kimia UIN Syarif Hidayatullah Jakarta. Email: evi@uinjkt.ac.id

Aditya Riky Nugroho, lahir di Jakarta, 29 September 1986, meraih gelar Sarjana Ekonomi (SE) jurusan Akuntansi pada tahun 2012 di UIN Syarif Hidayatullah Jakarta dan Magister Akuntansi (M.Ak) di Universitas Mercubuana pada tahun 2017. Saat ini bekerja sebagai dosen di Program Studi Akuntansi Universitas Pamulang Banten. Email: dosen02305@unpam.ac.id 